ARTICLE

\title{
Applicability of Finite Element Method to Collapse Analysis of Steel Connection under Compression
}

\author{
Zhiguang ZHOU $^{1,2, *}$, Akemi NISHIDA ${ }^{1}$ and Hitoshi KUWAMURA ${ }^{3}$ \\ ${ }^{1}$ Center for Computational Science and e-Systems, Japan Atomic Energy Agency,6-9-3 Higashiueno, Taito-ku, Tokyo, 110-0015, Japan \\ ${ }^{2}$ Dept. of Mechanics, School of Science, Wuhan University of Technology, Wuhan, 430070, China \\ ${ }^{3}$ Dept. of Architecture, School of Engineering, the University of Tokyo, 7-3-1 Hongo, Bunkyo-ku, Tokyo, 113-8656, Japan
}

\begin{abstract}
It is often necessary to study the collapse behavior of steel connections. In this study, the limit load of the steel pyramid-to-tube socket connection subjected to uniform compression was investigated by means of FEM and experiment. The steel connection was modeled using 4-node shell element. Three kinds of analysis were conducted: linear buckling, nonlinear buckling and modified Riks method analysis. For linear buckling analysis the linear eigenvalue analysis was done. For nonlinear buckling analysis, eigenvalue analysis was performed for buckling load in a nonlinear manner based on the incremental stiffness matrices, and nonlinear material properties and large displacement were considered. For modified Riks method analysis compressive load was loaded by using the modified Riks method, and nonlinear material properties and large displacement were considered.

The results of FEM analyses were compared with the experimental results. It shows that nonlinear buckling and modified Riks method analyses are more accurate than linear buckling analysis because they employ nonlinear, large-deflection analysis to estimate buckling loads. Moreover, the calculated limit loads from nonlinear buckling and modified Riks method analysis are close. It can be concluded that modified Riks method analysis is most effective for collapse analysis of steel connection under compression. At last, modified Riks method analysis is used to do the parametric studies of the thickness of the pyramid.
\end{abstract}

KEYWORDS: steel connection, collapse analysis, shell, Riks method, buckling load

\section{Introduction}

Steel connections are widely used in nuclear plants, buildings and other industries. ${ }^{1-3)}$ Damage happens frequently at the connections, for example, more than half of the accidents of nuclear plants have been found to occur in these areas. Thus it is necessary to study the behavior of connections under tensile, compressive, shear and bending loads. Besides experiments, finite element method is an important research method. Analysis of steel connections under compression is focused. An important problem of structural member under compression is buckling: ${ }^{3,4)}$ Some will buckle under plastic state, some even under elastic state. Buckle may take place locally, as a whole, or both. There are two categories of FEM buckling or collapse analyses, one is eigenvalue analysis which includes further two, linear buckling analysis and nonlinear buckling analysis according to whether nonlinear factor is considered; the other is modified Riks method, whose solution is viewed as the discovery of a single equilibrium path in a space defined by the nodal variables and the loading parameter, and the actual load value may increase or decrease as the solution progresses. Modified Riks method can give effective solution to high nonlinear buckling and collapse problem., ${ }^{5,6}$

In this study, the limit load of the steel pyramid-to-tube socket connection subjected to uniform compression was

*Corresponding author, E-mail: shu.shiko@jaea.go.jp

(C) 2011 Atomic Energy Society of Japan, All Rights Reserved. investigated by means of FEM and experiment. Three kinds of analyses were conducted: linear buckling, nonlinear buckling and modified Riks method analysis. The results of FEM analysis were compared with the experimental results. Moreover, modified Riks method analysis is used to conduct the parametric studies of the thickness of the pyramid.

\section{Experiment}

The specimen is made up by three parts: tube, pyramid and cover, as illustrated in Fig. 1. Three parts were joined together by welding. The tube is a general square steel tube $(\square-125 \times 4.5$, STKR 400$)$, the pyramid and the cover are made of general rolling steel plate (thickness $=4.5 \mathrm{~mm}$, SS400). In experiment, the cover was set to contact with the rigid loading plate linked with the piston head, and the tube was set to contact with the test-bed. The load was monotonic quasi-static compressive load. The load data was measured from the load cell installed at the piston head. The compressive deformation between the open end of the tube and the upper rigid loading plate was measured by four laser displacement sensors which were set up symmetrically around the specimen.

The limit load is $386 \mathrm{kN}$. The deformed specimen is illustrated in Fig. 2, which shows that the deformation concentrated at the pyramid-tube junction and that the tube remains square. 


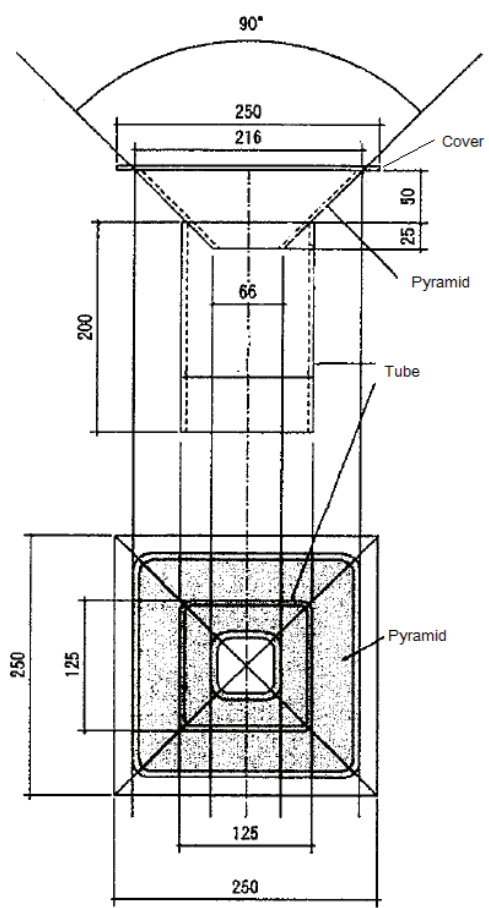

Fig. 1 Geometry of the specimen ${ }^{3)}$

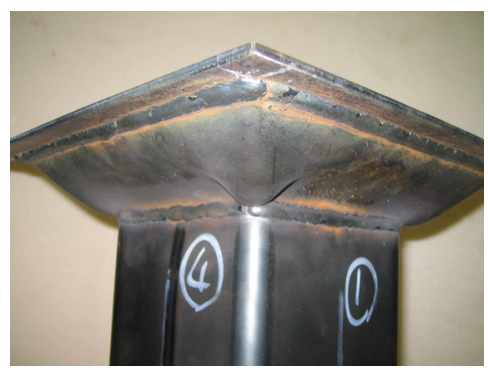

Fig. 2 Deformed specimen ${ }^{3)}$

\section{Finite Element Analyses}

\section{Finite Element Model}

The steel connection was modeled using a 4-node linear shell element with reduced integration. The finite element meshes are illustrated in Fig. 3. The model is turned upside down for visual convenience. There are 9484 elements and 9577 nodes in the model. The open end of the tube is pinned. The vertical pressure is applied to the cover by a point load at the center node whose vertical displacement degree coincides with that of all other nodes of the cover, which ensures the pressure is loaded in the same manner as the experiment. Material mechanical properties of the model are listed in Table 1. All the material properties are obtained from tensile tests.

Two commercial software packages, ABAQUS and Msc.Marc, were used to do the analyses. Linear buckling analysis and modified Riks method analysis were done by both software packages, while nonlinear buckling analysis by Msc.Marc. The three kinds of analysis are stated at section 2, section 3 and section 4, respectively. As the FE results by both software packages are almost the same, the result figures of linear buckling analysis and modified Riks

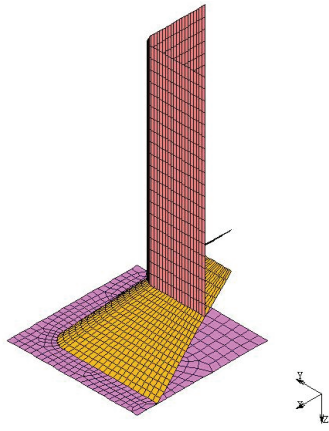

(a) 1/4 model

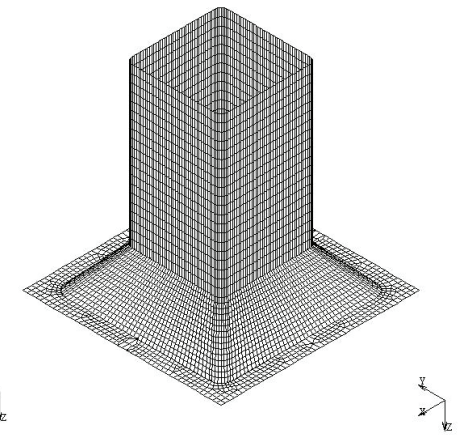

(b) Whole model

Fig. 3 Finite element model

Table 1 Material mechanical properties ${ }^{3)}$

\begin{tabular}{lcc}
\hline \multicolumn{1}{c}{ Steel type } & SS400 & STKR400 \\
\hline Measured plate thickness $(\mathrm{mm})$ & 4.2 & 4.2 \\
Young's modulus $\left(\mathrm{N} / \mathrm{mm}^{2}\right)$ & 204076 & 207893 \\
Yield strength $\left(\mathrm{N} / \mathrm{mm}^{2}\right)$ & 348 & 378 \\
Ultimate strength $\left(\mathrm{N} / \mathrm{mm}^{2}\right)$ & 433 & 454 \\
Uniform elongation $(\%)$ & 17 & 17 \\
Remarks & Pyramid, Cover & Tube \\
\hline
\end{tabular}

method analysis are generated by ABAQUS. However, the result figure of nonlinear buckling analysis is by Msc.Marc.

\section{Linear Buckling Analysis}

Linear buckling analysis can obtain the linear, elastic solutions of buckling loads with respect to various buckling modes. It detects the buckling of a structure when the structure's stiffness matrix approaches a singular value. In analysis of the steel connection, the initial load was taken as zero and therefore the buckling loads were simply to multiply the perturbation load by the eigenvalues.

The applied load is $100 \mathrm{kN}$ and eigenvalue of mode 1 is 19.097, so the buckling loads of mode 1 is $1909.7 \mathrm{kN}$. The buckling of mode 1 occurs near the open end of the tube. The displacement contour is illustrated in Fig. 4.

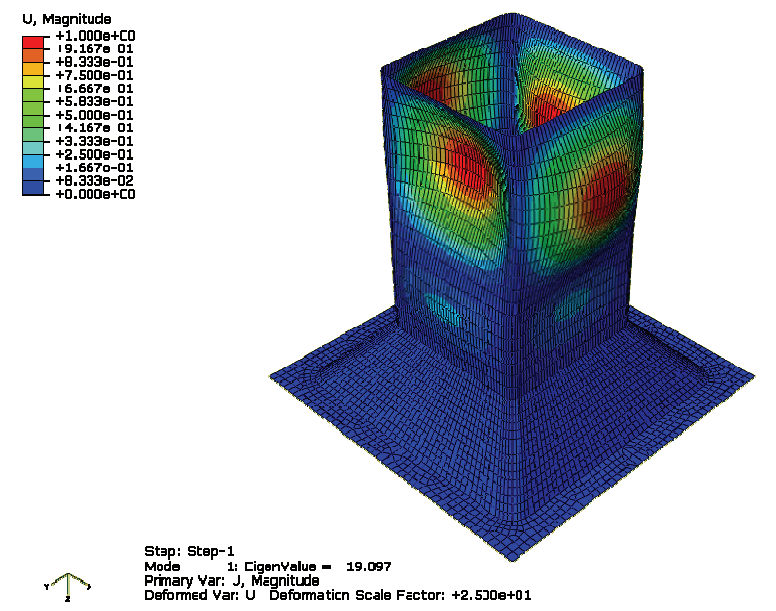

Fig. 4 Displacement contour at buckling Mode 1 (by linear eigenvalue buckling analysis) 


\section{Nonlinear Buckling Analysis}

Eigenvalue analysis can also be performed for buckling load in a nonlinear problem based on the incremental stiffness matrices, and here it is named nonlinear buckling analysis. It estimates the maximum load that can be applied to a geometrically nonlinear structure before instability happens. In a buckling problem that involves material nonlinearity of plasticity, the nonlinear problem must be solved incrementally. During this kind of analysis, nonpositive definite stiffness or a failure to converge in the iteration process signals the plastic collapse.

Nonlinear material properties and large displacement were considered in the nonlinear buckling analysis of the steel connection. The applied load increases to $370 \mathrm{kN}$ by 37 increments, and the buckling load is estimated after every load increment by using the BUCKLE INCREMENT option in Msc.Marc. The buckling load is estimated by: ${ }^{7)}$

$$
P+\lambda \Delta P \text {, }
$$

where $P$ is the load applied at the beginning of the increment prior to the buckling analyses, $\Delta P$ is the incremental load of current increment, and $\lambda$ is the eigenvalue obtained by the Lanczos method. Table 2 shows the buckling loads after increment $10,20,30,35$ and 37 . The buckling load tends to converge at load increment 37 . The buckling after load increment 10 and 20 happens near the open end of the tube as the previous linear eigenvalue buckling analysis, while the buckling after load increment 35 and 37 happens at the pyramid-tube junction. The displacement contour of the buckling after load increment 37 is illustrated in Fig. 5.

Table 2 Buckling load estimated after load increments

\begin{tabular}{ccccc}
\hline $\begin{array}{c}\text { No. of incre- } \\
\text { ment }\end{array}$ & $\begin{array}{c}P \\
(\mathrm{kN})\end{array}$ & $\begin{array}{c}\Delta P \\
(\mathrm{kN})\end{array}$ & $\lambda$ & $\begin{array}{c}\text { Buckling load } \\
(\mathrm{kN})\end{array}$ \\
\hline 10 & 90 & 10 & 161.3 & 1703 \\
20 & 190 & 10 & 150.7 & 1697 \\
35 & 340 & 10 & 6.0 & 399.7 \\
37 & 360 & 10 & 1.6 & 376.4 \\
\hline
\end{tabular}
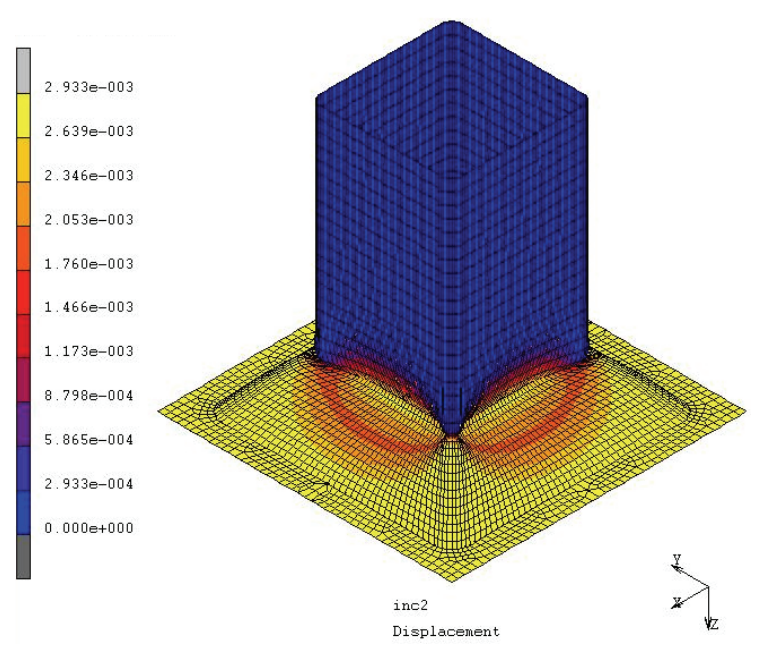

Fig. 5 Displacement contour at limit load (by nonlinear buckling analysis)

\section{Modified Riks Method Analysis}

It is often needed to seek nonlinear static equilibrium solutions for unstable problems, where the response of loaddisplacement can show high nonlinear behavior-that is, during periods of the response, the load and/or the displacement may reduce as the solution progresses. The modified Riks method is an algorithm that gives effective solution of such cases.

The Riks method takes the load magnitude as still unknown; it solves concurrently for loads and displacements. Therefore, another variable must be specified to measure the progress of the solution; Abaqus/Standard uses the "arc length", $l$, along the static equilibrium path in load-displacement space. This approach provides solutions in spite of whether the response is stable or unstable. As the loading magnitude is among the solution, a method is necessary to specify when the step is ended. A maximum displacement value at a specified degree of freedom or a maximum value of the load proportionality factor can be specified. The step will be stopped when either value is ex(eeded. ${ }^{\text {) }}$

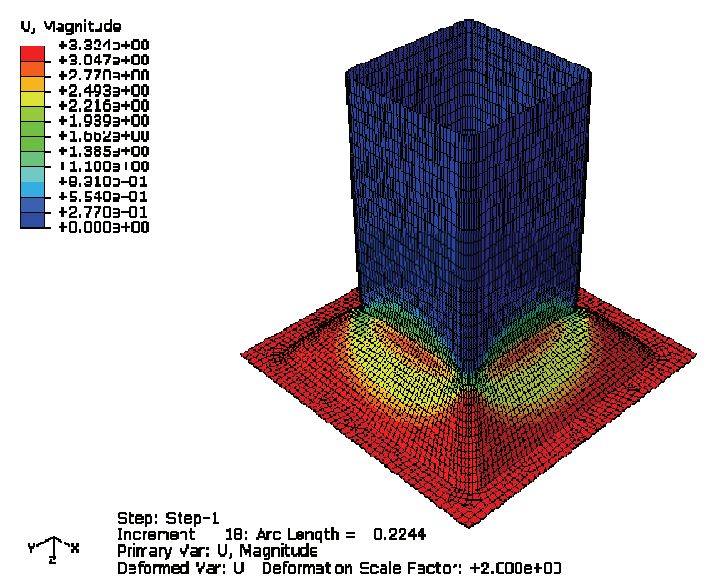

Fig. 6 Displacement contour at limit load (by modified Riks method Analysis)

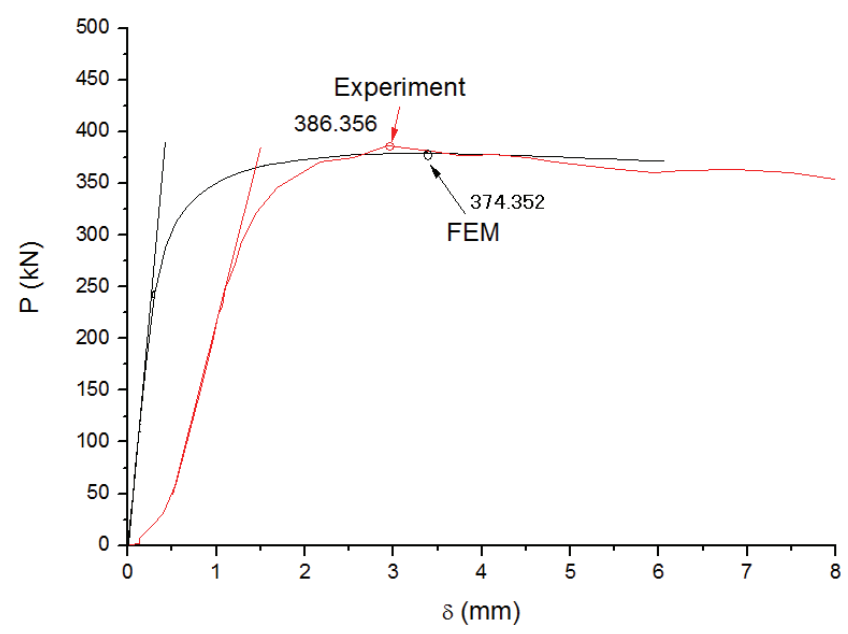

Fig. 7 Load-deformation curve 
Nonlinear material properties and large displacement were considered in the modified Riks method analysis of the steel connection. The displacement contour at limit load is illustrated in Fig. 6. The load-deformation curve of analysis and experiment is illustrated in Fig. 7, where $P$ is the load, $\delta$ is the compressive deformation of the steel connection and the circle symbols mean limit load points. Figure 7 shows that the calculated elastic stiffness is higher than the experimental one, which can be explained that the compressive deformation of the pad below the specimen was involved in $\delta$ in the experiment.

\section{Comparison of Experimental and FE Results}

Linear buckling and nonlinear buckling analysis are both eigenvalue analyses. The displacement results are relative value, rather than real value, and there is no stress result. But modified Riks method analysis is a static equilibrium analysis where the displacement and stress results are the real value. So only modified Riks method analysis can output load-deformation curve.

Regarding simulating the deformation pattern and limit load of the experiment, it shows that the nonlinear buckling and the modified Riks method analysis perform pretty well, yet the linear buckling analysis is less good. The calculated limit loads from the nonlinear buckling analysis and the modified Riks method analysis are close. Moreover, the load-deformation curve from the modified Riks method analysis corresponds well to that of the experiment by getting rid of the initial slippage and the deformability of the experimental apparatus.

From above results, it can be concluded that modified Riks method analysis is most effective for collapse analysis of steel connection under compression.

\section{Parametric Studies}

In this part, modified Riks method analysis is used to do the parametric studies of " $t p$ ", the thickness of the pyramid.

The nominal yield axial force of the tube is, nominal (yield strength) $\times($ section area $)=235 \mathrm{MPa} \times 2117 \mathrm{~mm}^{2}=$ $500 \mathrm{kN}^{3)}$ While the limit load of the experiment is $386 \mathrm{kN}$. In order to keep the yield axial force of the tube, thicker thickness or high strength steel is needed for the pyramid. Here $t p$ is set to $3,4.2,5,6,8,10 \mathrm{~mm}$ (six models) to study the problem. The thickness of the tube and the cover is unchanged as $4.2 \mathrm{~mm}$.

The displacement contours at limit load of the six models are illustrated in Fig. 8, and the load-deformation curves are illustrated in Fig. 9. It can be seen that the deformation concentrated at the pyramid-tube junction for the thickness value of 3, 4.2, 5 and $6 \mathrm{~mm}$, while the deformation concentrated at the tube for the thickness value of 8 and $10 \mathrm{~mm}$. Moreover the load decreases rapidly after limit load for the case of 8 and $10 \mathrm{~mm}$. It can be explained as due to the behavior of the buckling of the tube.

The correlation of limit load and $t p$ is illustrated in Fig. 10. The limit load is proportional to $t p$ between $3-8 \mathrm{~mm}$. The

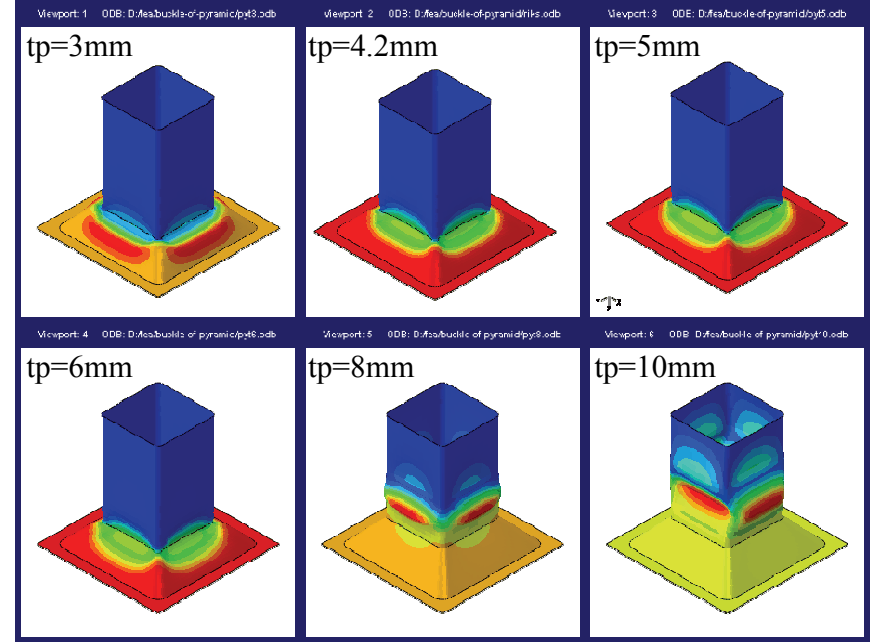

Fig. 8 Displacement contours at limit load of the six models

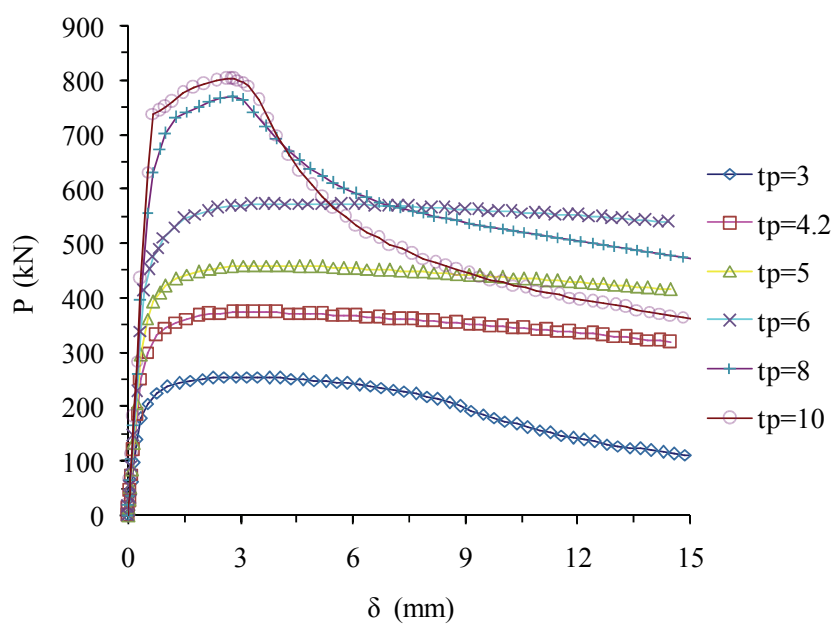

Fig. 9 Load-deformation curves of the six models

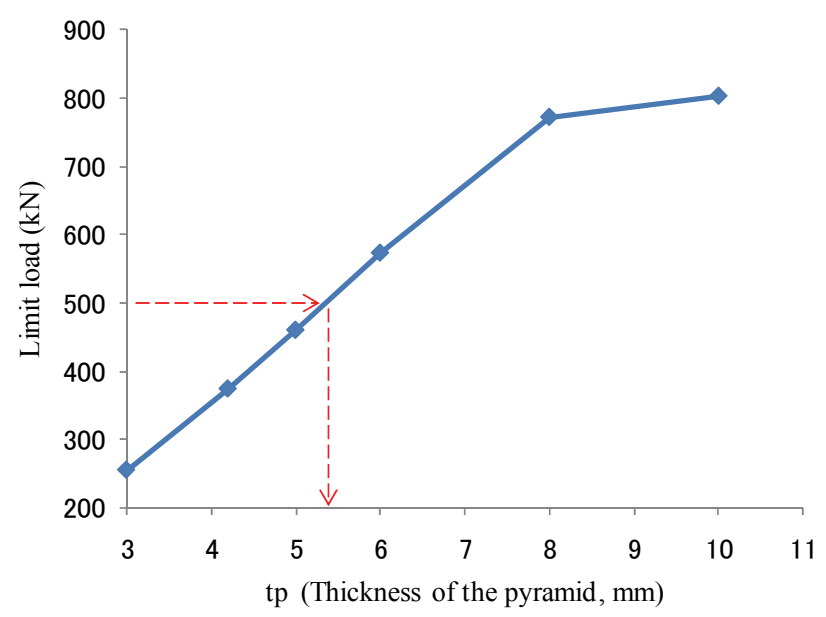

Fig. 10 Correlation of limit load and thickness of the pyramid

nominal yield axial force of the tube $(500 \mathrm{kN})$ can be obtained when $t p=5.4 \mathrm{~mm}$, as estimated from Fig. 10 . 


\section{Conclusions}

The limit load of the steel pyramid-to-tube socket connection subjected to uniform compression was investigated by means of FEM and experiment. Three kinds of analysis were done: linear buckling analysis, nonlinear buckling analysis and modified Riks method analysis. The results of FEM analyses were compared with the experimental results. Moreover, modified Riks method analysis is used to do the parametric studies of the thickness of the pyramid. It can be concluded that:

(1) In the simulation of the deformation pattern and limit load of the experiment, it shows that the nonlinear buckling analysis and the modified Riks method analysis perform pretty well, yet the linear buckling analysis is less good.

(2) The calculated limit loads from the nonlinear buckling analysis and the modified Riks method analysis are approximate to each other.

(3) The load-deformation curve from the modified Riks method analysis corresponds well to that of the experiment.

(4) Modified Riks method analysis is most effective for collapse analysis of steel connection under compression.

(5) The deformation concentrated at the pyramid-tube junction when the thickness of the pyramid is relatively small, while at the tube when the pyramid is thick enough.

(6) The limit load comes proportional to the thickness of the pyramid between $3-8 \mathrm{~mm}$ if the thickness of the tube and the cover remains $4.2 \mathrm{~mm}$.

(7) As estimated from the parametric studies, the nominal yield axial force of the tube can be obtained when $t p=5.4 \mathrm{~mm}$.

\section{References}

1) AIJ, Preliminary Reconnaissance Report of the 1995 Hyogoken-Nanbu earthquake (English edition), Tokyo, Japan, (1995).

2) Z. Zhou, H. Kuwamura, "Geometrical and metallurgical notches of welded joints of steel beam-to-column connections: stress-strain states at steel connections part 4," J. Struct. Constr. Eng., 74[3], 551-559 (2009). [in Japanese]

3) H. Kuwamura, T. Ito, "Compressive strength of hollow pyramid connector on square tube," J. Struct. Constr. Eng., 74[4], 731-737 (2009). [in Japanese]

4) J. Becque, K. J. R. Rasmussen, "Numerical investigation of the interaction of local and overall buckling of stainless steel i-columns," J. Struct. Eng., 135[11], 1349-1356 (2009).

5) M. A. Crisfield, "A fast incremental/iteration solution procedure that handles 'snap-through'," Comput. Struct., 13, 55-62 (1981).

6) Hibbit, Karlsson, Sorensen, ABAQUS Inc. ABAQUS standard user's manual, v6.5, Pawtucket,R.I. (2005).

7) MSC.Software Corporation, MSC.Marc Volume A: Theory and User Information, v2000, Santa Ana (2001). 